\title{
UAB: democratização do ensino superior público ou reprodução das desigualdades?
}

Resumo: O artigo apresenta e analisa o panorama da formação de professores realizada por meio da Educação a Distância (EaD), vinculados ao sistema Universidade Aberta do Brasil (UAB). O objetivo foi investigar se as atuais políticas públicas, efetivadas pelo sistema UAB, democratizam o ensino superior público. Para isso, busca-se uma série de dados estatíscos para contextualizar a formação de professores realizada por meio da EaD. As políticas públicas têm priorizado a modalidade a distância para amenizar a histórica necessidade de formação de professores no Brasil e assim universidades públicas são chamadas para, num curto período de tempo, formar um grande número de professores. A pesquisa é de natureza exploratória, descritiva e de abordagem qualitativa e quantitativa. Para a coleta e análise de dados foi realizado um mapeamento sobre a formação de professores realizada na modalidade a distância, por meio da Universidade Aberta do Brasil, o qual foi efetivado em âmbito nacional e tendo como base de dados os portais: UAB, Coordenação de Aperfeiçoamento de Pessoal de Nível Superior (CAPES), Instituições Públicas de Ensino Superior (IPES). Utilizou-se também dados do Censo da Educação Superior e do Instituto Brasileiro de Geografia e Estatística (IBGE). Com base neste cenário, o artigo desenvolve-se a partir de dois pontos principais: a expansão e a interiorização do ensino superior público e a política de formação de professores na modalidade a distância.

Palavras-chave: Educação a distância. Formação de professores. Ensino superior. Universidade Aberta do Brasil.

\section{Introdução}

Ao analisar a história da Educação a distância no Brasil, pode-se afirmar que o momento atual está caracterizado pelo forte investimento na modalidade por meio de políticas governamentais que visam especialmente fomentar a formação dos professores, foco do sistema Universidade Aberta do Brasil (UAB). De acordo com Giolo (2010, p. 1275) políticas, que inicialmente estavam vinculadas ao ensino presencial, modificam-se e "começam a ser montados, pelas instituições públicas, programas de formação de professores: formação continuada e, principalmente, programas destinados a titular professores leigos", como o sistema UAB.

A partir da Lei de Diretrizes e Bases da Educação Nacional (LBDN), Lei no 9.394/1996 -, cujos artigos 80 e 87 referem-se à Educação a distância, são promulgados uma série de atos normativos, demarcando assim um processo de reconhecimento da modalidade no país. (BRASIL, 1996) Esta crescente notoriedade da EaD 
(1) Programa pró-licenciatura. Disponível em: http://portal.

mec.gov.br/index.php?ltemid

$=708 \&$ id $=12349$ \&option $=\mathrm{C}$

om Content\&view=article. Acesso

em: 20 abr 2012

(3) O Sistema Universidade Aberta do Brasil (UAB), foi criado em 2005 no âmbito do Fórum das Estatais pela Educação e oficializado em 2006 pelo Decreto $n^{\circ} 5.800$, de 8 de junho de 2006

(4) A pesquisa Acompanhamento e avaliação de políticas e experiências de formação de professores na modalidade a distância (2011-2012) é parte dos estudos do grupo Comunic, inscrito no Laboratório de Novas Tecnologias do Centro de

Educação da Universidade Federal de Santa Catarina

(Lantec/CED/UFSC) tem reflexos nas políticas públicas educacionais. Dourado (2008, p. 900), por exemplo, salienta que "a partir da segunda metade da década de 1990, [a EaD] passou a ocupar espaço de referência para as políticas de expansão e, particularmente, para a formação de professores".

Deste modo, é durante o período transcorrido entre os anos finais de 1990 e os primeiros anos de 2000 que se estabelecem as principais leis que dão sustentação à modalidade, a qual se estrutura num discurso político de expansão, interiorização e democratização do ensino superior. Essa política materializa-se nas universidades públicas especialmente a partir de 2004 quando os primeiros editais (Programa Prolicen) ${ }^{1}$ são lançados pelo Ministério da Educação para oferta de cursos de licenciatura a distância. Na sequência, em $2005,{ }^{3}$ a criação da UAB e, por meio dela, a expansão das formações a distância.

É com base neste discurso que traz a EaD como possibilidade de democratizar o ensino superior no Brasil que se realizou uma pesquisa ${ }^{4}$ com objetivo de acompanhar e avaliar a formação de professores realizada via UAB. Neste artigo apresenta-se um recorte desta pesquisa, onde se pretende problematizar as políticas públicas para a educação a distância, projetando indícios que auxiliem a responder a pergunta: A EaD contribui para minimizar a diferença de oferta de cursos e vagas, no ensino superior público, entre as regiões do país?

\section{O discurso da democratização do ensino superior público a partir da UAB}

Conforme mencionado acima, os anos 2000 caracterizam-se como relevantes para a Educação a Distância no Brasil, pois neste período uma série de leis, decretos e portarias foram aprovadas com vistas à expansão e interiorização do ensino superior por meio da EaD. É neste período que aparecem os grandes programas governamentais para a educação, entre eles, o Prolicen e, especialmente, a constituição do sistema Universidade Aberta do Brasil a partir do Decreto $\mathrm{n}^{\circ} 5.800 / 06$, o qual decreta:

Art. $1^{\circ}$ Fica instituído o Sistema Universidade Aberta do Brasil - UAB, voltado para o desenvolvimento da modalidade de educação a distância, com a finalidade de expandir e interiorizar a oferta de cursos e programas de educação superior no País. Parágrafo único. São objetivos do Sistema UAB:I - oferecer, 
prioritariamente, cursos de licenciatura e de formação inicial e continuada de professores da educação básica;[...]IV - ampliar o acesso à educação superior pública; $V$ - reduzir as desigualdades de oferta de ensino superior entre as diferentes regiões do País; [… (BRASIL, 2006, grifo nosso).

A redefinição política revela que os encaminhamentos legais se dão de forma dispersa e que é através da formação de professores que o Ministério da Educação (MEC) tenta associar educação básica e ensino superior. Um dos aspectos importantes desta redefinição é a assim chamada, nova CAPES, a qual passa a ter atuação ampliada a partir de 2007, contemplando também a formação de professores da educação básica. Neste contexto, a EaD, sobretudo a partir da UAB, ganha destaque e a democratização do acesso à educação representa um de seus desafios. (DOURADO, 2008) Litwin (2001, p. 21) corrobora com Dourado (2008) neste ponto, quando afirma que "o verdadeiro desafio [da EaD] continua sendo seu sentido democratizante".

De acordo com o portal da CAPES/UAB, o sistema Universidade Aberta do Brasil fundamenta-se em cinco eixos que buscam a consolidação de uma política para a formação de professores e a expansão do ensino superior. O primeiro destes eixos diz respeito à "expansão pública da educação superior, considerando os processos de democratização e acesso".

A democratização do ensino superior por meio da educação a distância é um tema polêmico, controverso e que engendra uma gama de reflexões e discussões, visto que é temática de textos e pesquisas recentes. Para Santos (2011, p. 10), por exemplo, "democratização não seria apenas o aumento quantitativo das vagas, mas também a diversificação dos currículos profissionais". Gatti (2009) lembra que a Organização das Nações Unidas para a Educação, a Ciência e a Cultura (UNESCO) - ainda em sua Conferência Mundial sobre Ensino Superior convocada em 1998 tenha apontado restrições quanto à educação a distância, sobretudo em países subdesenvolvidos por questões de infraestrutura - aponta que as tecnologias de informação e comunicação (TIC) têm importante papel na superação dos problemas relativos ao acesso à educação e que, consequentemente, isso possibilitaria a democratização do ensino superior. Vargas (2007, p. 1) considera as questões sociais atreladas à democratização, ao afirmar que "a real democratização do ensino superior" é promovida a partir do momento em que
(5) Disponível em: http:// www.uab.capes.gov.br/ index.php?option $=$ com content\&view $=$ article\&i $\bar{d}=$ 9\&ltemid=21. Acesso em: 15 mar. 2011. 
a expansão "agregue não apenas mais alunos, mas que se possa perceber uma maior interdependência entre suas origens sociais e seu desempenho acadêmico". Alonso (2010, p. 1320) salienta que "no mote da expansão da EaD, dois temas são recorrentes: a democratização do acesso ao ensino superior e a necessidade da formação dos profissionais da educação, como fator para melhoria da qualidade do ensino fundamental e médio". Nesse sentido a democratização não pode ser vista apenas como aumento do número de vagas, demanda equidade entre as regiões e acesso as classes historicamente excluídas desse nível de ensino.

Litwin (2001, p. 20), revela que o discurso que relaciona EaD e democratização da educação não se restringe apenas ao contexto brasileiro, uma vez que também é percebido em nível de América Latina. A autora ressalta que:

[...] no âmbito da educação, as primeiras perguntas que é preciso fazer referem-se a questões de tipo político: a oferta está aumentando como resposta a um crescimento da demanda ou é ela que gera uma nova demanda? Os aspectos educacionais estão sendo democratizados, de forma a permitir que setores que antes não tinham acesso à educação passem a ter? Novos espaços estão sendo criados, promovendo, por sua vez, novas marginalizações? Essas três perguntas, inseridas na problemática de uma política educacional, permitem-nos identificar o âmbito político quem que se inscreve o projeto [a EaD].

No entanto, ainda que se configure como uma discussão recorrente nota-se que não existe uma conceituação específica sobre a democratização do ensino superior. Cabe ressaltar que este artigo não pretende delimitar um conceito linear sobre o assunto, mas visa tecer algumas reflexões sobre a temática a partir do referencial teórico e dos resultados de uma pesquisa de maior escala, da qual este estudo é parte integrante.

Sendo assim, antes de discorrer sobre a propalada democratização do ensino superior público é preciso trazer à tona o que se entende por "democratização" para então tentar, desafiadoramente, responder: A EaD contribui para minimizar a diferença de oferta de cursos e vagas no ensino superior público? Não se nega aqui a importância de políticas que visem à expansão do ensino superior público. Pelo contrário: o questionamento reside em se de fato esta 
política democratiza o ensino superior público ou se mantem e/ou amplia as históricas diferenças entre as regiões do país.

Neste sentido, a fim de esclarecer este termo desde suas bases primárias, toma-se o verbete "democratizar", cuja definição é "2 t.d. e pron. tornar(-se) popular; colocar(-se) ao alcance do povo, da maioria da população < a universidade democratizou-se neste governo >". (DEMOCRATIZAR, 2009, p. 612) Chama a atenção o fato do uso de um exemplo voltado à temática deste artigo, o que auxilia ainda mais na compreensão do termo no contexto da Educação e salienta a importância dessa discussão. Além disso, segundo Preti (2005, p. 32), a EaD "é tida como uma alternativa viável à democratização das oportunidades educacionais no país, compreendendo a democratização como acesso, permanência e qualidade de ensino".

Deste modo, concebemos democratização do ensino superior a partir da perspectiva da garantia de acesso e permanência a este nível educacional por parte de todos os cidadãos aptos a nele ingressar, como forma de minimizar as restrições financeiras e geográficas dos estudantes, contribuindo assim para um maior desenvolvimento socioeconômico.

\section{Os dados mostram que...}

Com o objetivo de visualizar o panorama nacional das universidades vinculadas ao sistema UAB que ofertam cursos de formação de professores na modalidade a distância, realiza-se inicialmente uma busca no site da CAPES/UAB, onde foram encontradas 75 Instituições Públicas de Ensino Superior (IPES), das quais 48 referem-se à instituições federais e 27 pertencem à esfera estadual. ${ }^{6}$ Identificadas as instituições, num segundo momento procura-se revelar, ainda na mesma base de dados, os cursos de formação de professores em nível de licenciatura e especialização em cada instituição elencada na fase anterior.

No intuito de conferir os dados referentes aos cursos de formação de professores (licenciatura e especialização), inicia-se uma busca nos portais de educação a distância das instituições públicas de ensino superior (IPES/EaD). No entanto, a partir de uma comparação prévia no que diz respeito ao número de cursos ofertados, constata-se uma discrepância entre as informações disponibilizadas pelas IPES/EaD e pela CAPES/UAB.
(6) Mapeamento realizado em Setembro de 2010 . 
(7) Portal SisUAB: http://www uab.capes.gov.br/sisuab/ Login input.action. "O SisUAB é uma plataforma de suporte para a execução, acompanhamento e gestão de processos da Universidade Aberta do Brasil. Está preparado para o cadastramento e consulta de informações sobre instituições, polos, cursos, material didático, articulações, colaboradores e mantenedores" Disponível em: http://capes.gov. br/educacao-a-distancia/sisuab. Acesso em 25 mar. 2012
De antemão, essa discrepância sinaliza possíveis dificuldades na publicação dos dados divulgados pelas CAPES/UAB, uma vez que o portal não especifica a data de atualização dos dados. Vale ressaltar que a opção pela CAPES/UAB como ponto de partida para o mapeamento dos dados deve-se ao fato de que, em tese, este seria o local indicado para encontrar os dados oficiais referentes à formação de professores por meio da UAB. Registra-se ainda, a dificuldade de encontrar em bases oficiais uma sistemática de dados unificada e completa. O SisUAB ${ }^{7}$, por exemplo, seria outra importante instância oficial de coleta de dados sobre o alcance da UAB, mas o portal apresenta dois entraves: o primeiro, é que este sistema não está aberto à consulta pública em geral, já que é necessário senha e usuário previamente autorizado - geralmente restrito aos que ocupam cargo de coordenador; e o segundo, é que as informações não seguem um padrão de atualização, de modo que algumas instituições e/ou cursos apresentam um esboço de sua realização ao longo do tempo, ao passo que em outras apenas estão disponíveis os dados de cadastramento. O impedimento encontrado quando da tentativa de trabalhar com informações oficiais foi também relatado por Barreto (2008) em seu texto sobre as tecnologias na política nacional de formação de professores via EaD.

Tendo em vista este cenário, concorda-se com Gatti (2009, p. 103) quando afirma que "a sistemática de coleta de dados dessa modalidade [a EaD] ainda não está inteiramente consolidada". Nota-se, por exemplo, que em alguns casos os cursos apresentados na CAPES/UAB não constam na respectiva IPES, aspecto que conduz a dúvidas sobre a real oferta do curso pela instituição. Isto, aliás, acarreta um questionamento sobre a forma como tais dados são divulgados e acerca da validade das avaliações oficiais referentes à UAB, uma vez que os dados apresentam incoerências.

Ao considerar este contexto de inexatidão e por julgar que as IPES/EaD têm mais condições de informar dados atualizados que a CAPES/UAB - uma vez que se responsabilizam apenas por suas próprias informações ao passo que a CAPES/UAB ocupa-se da totalidade das instituições em âmbito nacional - decide-se então analisar somente os dados fornecidos pelas IPES/EaD. Deste modo, o Quadro 1 apresenta a quantidade de cursos ofertados para a formação de professores (Licenciatura e Especialização) em cada região do Brasil, segundo os portais esse portal. 
Quadro 1- Oferta de cursos de formação de professores EaD (setembro/2010)

\begin{tabular}{|l|l|l|l|}
\hline \multicolumn{4}{|c|}{ IPES/EaD } \\
\hline & Licenciatura & Especialização & Total \\
\hline Norte & 27 & 7 & 34 \\
\hline Nordeste & 60 & 11 & 71 \\
\hline Sudeste & 39 & 11 & 50 \\
\hline Sul & 44 & 39 & 83 \\
\hline Centro-oeste & 34 & 9 & 43 \\
\hline Total & 204 & 77 & 281 \\
\hline
\end{tabular}

Estas informações permitem identificar o alcance da UAB e a consequente expansão da educação a distância no país, observando a diferença de oferta de cursos entre as regiões geográficas. O levantamento realizado a partir das IPES/EaD indica o Sul como a região mais representativa em relação ao número de cursos ofertados, seguida pelo Nordeste e Sudeste. É interessante notar que a região Sul, a menor em termos de extensão territoria $1^{8}$ e a terceira em população, ${ }^{9}$ possui a maior oferta de cursos. Além disso, neste último quesito, o Sudeste e o Centro-oeste ocupam a terceira e quarta colocação (ver Tabela 1). Em outras palavras, isto significa que as três regiões mais desenvolvidas do Brasil concentram a maior parte dos cursos: Sul, Sudeste e Centro-oeste oferecem em conjunto 167 cursos. Em contrapartida, as regiões Norte e Nordeste, as mais empobrecidas do país e onde se apresenta uma defasagem histórica na oferta do ensino superior público, registram uma menor oferta de cursos (105), mesmo o Nordeste sendo a segunda região na oferta de Cursos. Neste sentido, cabe perguntar: o cenário da oferta de cursos por meio da UAB não deveria privilegiar as regiões tradicionalmente carentes de oferta de ensino superior?

Contudo, considera-se que a discussão que se apresenta estaria comprometida se pautada somente no número de habitantes ou condição socioeconômica das regiões brasileiras. Neste sentido, torna-se importante acrescentar os dados referentes à parte da população que se encontra apta ao ingresso no ensino superior ${ }^{10}$. Deste modo, apresentam-se as seguintes tabelas: o Quadro 2 especifica o número geral e por região de concluintes do ensino médio nos anos de 2009 e 2010; e o Quadro 3 categoriza estes dados por faixa etária.
(8) Relação região/extensão territorial de acordo com o Instituto Brasileiro de Geografia e Estatística (IBGE): Norte/ 3.8523.327.229 $\mathrm{Km}^{2}$, Centro-oeste/ 1.606.371.505 $\mathrm{Km}^{2}$, Nordeste/ 1.554.257.004 $\mathrm{Km}^{2}$, Sudeste/ $924.511 .292 \mathrm{Km}^{2} \mathrm{e}$ Sul/ 576.409.569 Km². Disponível em: http://www.ibge.gov.br/home/ geociencias/areaterritorial/principal. shtm. Acesso em: 17 mar. 2012.

(9) Relação região/população de acordo com o Instituto Brasileiro de Geografia e Estatística (IBGE): Sudeste/77.656.762 habitantes, Nordeste/51.871.449, Sul/27.022.098, Norte/15.484.929 e Centro-oeste/13.677.475. Disponível em: http://www.ibge.gov.br/home/. Acesso em: 17 mar. 2012.

(10) Os Quadros 2 e 3 têm como fonte os dados do INEP - Censo da Educação Básica 2009 e 2010. Disponível em: http://portal.inep. gov.br/basica-censo-escolarsinopse-sinopse. Acesso em: 17 mar 2012. 
(11) Conforme dados do Censo do Ensino Superior de 2010.

(12) Conforme informações contidas em http://www.ibge.gov.br/ home/presidencia/noticias/noticia visualiza.php?id_noticia $=2057 \&$ id $^{-}$ pagina $=1$. Acesso em: 20 e mar. 2012 os percentuais das demais regiões são: Nordeste - 28,7\%; Norte - 14,4\%; Sul - 5,3\%; e CentroOeste $-1,8 \%$.

(13) Segundo o IBGE 'aglomerado subnormal' é um termo geral que abrange "a diversidade de assentamentos irregulares existentes no país, conhecidos como favelas, invasões, grotas, baixadas, comunidades, vilas, ressacas mocambos, palafitas, entre outros". Disponível em:

http://www.ibge.gov.br/home/ presidencia/noticias/noticia visualiza . php? id noticia $=2051$. Acesso em: 17 mar. 2012. Mais informações: http://www. ibge.gov.br/home/presidencia/ noticias/noticia visualiza.php?id noticia $=2057 \&$ id pagina $=1$
Quadro 2 - Concluintes do Ensino Médio no Brasil e por região geográfica

\begin{tabular}{|l|l|l|}
\hline & $\mathbf{2 0 0 9}$ & $\mathbf{2 0 1 0}$ \\
\hline Brasil & 1.797 .434 & 1.793 .167 \\
\hline Norte & 146.188 & 147.325 \\
\hline Nordeste & 540.692 & 530.524 \\
\hline Sudeste & 741.767 & 760.133 \\
\hline Sul & 247.073 & 232.642 \\
\hline Centro-oeste & 121.714 & 122.543 \\
\hline
\end{tabular}

Quadro 3 - Concluintes do Ensino Médio por faixa etária no Brasil e por região geográfica

\begin{tabular}{|c|c|c|c|c|c|c|c|}
\hline & & Brasil & Norte & Nordeste & Sudeste & Sul & $\begin{array}{l}\text { Centro- } \\
\text { Oeste }\end{array}$ \\
\hline \multirow{2}{*}{$\begin{array}{l}\text { De } 0 \text { a } \\
16 \text { anos }\end{array}$} & 2009 & 62.099 & 5.972 & 25.055 & 8.125 & 14.917 & 8.030 \\
\hline & 2010 & 63.310 & 6.307 & 27.003 & 8.476 & 13.490 & 8.034 \\
\hline \multirow{2}{*}{$\begin{array}{l}\text { De } 17 \text { a } \\
19 \text { anos }\end{array}$} & 2009 & 1.465 .616 & 100.979 & 394.347 & 666.441 & 208.447 & 95.402 \\
\hline & 2010 & 1.437 .477 & 98.622 & 357.132 & 685.547 & 198.350 & 97.826 \\
\hline \multirow{2}{*}{$\begin{array}{l}\text { De } 20 \text { e } \\
21 \text { anos }\end{array}$} & 2009 & 115.413 & 16.359 & 48.319 & 31.478 & 11.458 & 7.799 \\
\hline & 2010 & 124.644 & 17.797 & 57.883 & 31.800 & 10.109 & 7.055 \\
\hline \multirow{2}{*}{$\begin{array}{l}\text { De } 22 \text { a } \\
24 \text { anos }\end{array}$} & 2009 & 58.368 & 9.229 & 28.401 & 12.267 & 4.706 & 3.765 \\
\hline & 2010 & 62.488 & 10.061 & 33.830 & 11.184 & 4.104 & 3.309 \\
\hline \multirow{2}{*}{$\begin{array}{l}\text { De } 25 \text { a } \\
29 \text { anos }\end{array}$} & 2009 & 40.200 & 6.538 & 19.789 & 8.135 & 3.102 & 2.636 \\
\hline & 2010 & 43.618 & 6.858 & 24.037 & 7.729 & 2.685 & 2.309 \\
\hline \multirow{2}{*}{$\begin{array}{l}\text { Mais de } \\
29 \text { anos }\end{array}$} & 2009 & 55.738 & 7.111 & 24.781 & 15.321 & 4.443 & 4.082 \\
\hline & 2010 & 61.630 & 7.680 & 30.639 & 15.397 & 3.904 & 4.010 \\
\hline
\end{tabular}

Considerando os números do Quadro 2, a região Sudeste deveria ter a maior oferta de cursos na modalidade a distância, visto que conta com o maior número de concluintes no ensino médio e que dos seus 13.481 cursos de graduação presencial oferecidos em 2010, ${ }^{11} 10.894$ são ofertados pelo setor privado, ou seja, apenas 19,19\% deles são de instituições públicas. Sabe-se que esta é uma das regiões mais desenvolvida e rica do país, em termos financeiros, mas há que se considerar que ela é, ao mesmo tempo, palco de grandes desigualdades sociotécnicas e culturais. O Censo 2010 identificou que esta região é responsável por $49,8 \%{ }^{12}$ dos domicílios classificados como aglomerados subnormais existentes no Brasil. ${ }^{13}$ A fim de 
atender a essa parte da população, que provavelmente não tem condições de acessar e manter-se numa instituição privada, é que se faz necessária uma oferta maior de cursos superiores públicos. Somada à questão socioeconômica, o Quadro 3 mostra que a região Sudeste é responsável por 24,44\% (2009) e por $21,97 \%$ (2010) dos formandos do ensino médio com idade superior a 25 anos. Além disso, observa-se um aumento significativo da formação em nível médio entre estudantes com idade superior a 29 anos. A região Norte, por sua vez, corresponde ao maior território brasileiro, mas ocupa a quarta posição em número de concluintes do ensino médio e em oferta de cursos públicos de graduação presencial. Além disso, como já mencionado, é uma das regiões economicamente mais pobres do país e que conta com a pior oferta em número de cursos a distância no Brasil: somando-se os cursos ofertados por instituições públicas (presenciais e a distância) nesta região, chega-se a um total de 1.182. Este número, ainda que somado, não alcança nem sequer o número de cursos de instituições públicas presenciais do Sul (1.642), região que tem a maior oferta de cursos EaD. Na contramão desses dados, o Censo do Professor da Educação Básica de $2009^{14}$ indica que a região Norte tem apenas 54,02\% de seus professores da educação básica com formação superior, e ainda: considerando apenas os que têm graduação com licenciatura esse percentual diminui para 47,50\%. Isso indica que a região Norte tem uma grande demanda para cursos de graduação, a qual não está sendo devidamente atendida. Além disso, o baixo número de concluintes do ensino médio, registrado na região Norte em comparação com as demais regiões do país, sugere uma defasagem na oferta da educação básica, fato que indica a necessidade de incremento na oferta de formação de professores. É importante relembrar que o sistema UAB tem seus fundamentos elaborados, entre outros aspectos, em virtude de um possível "apagão do ensino médio", ${ }^{15}$ e assim sua importância nesta região é crucial para elevar os índices educacionais, assim como proporcionar a melhoria da educação como um todo na região.

No que se refere ao número de concluintes do ensino médio com mais de 25 anos (Quadro 3), o Nordeste apresenta os maiores aproveitamentos. Isto, em tese, demanda uma maior oferta de cursos superiores, mas são as IPES da região Sul que oferecem o maior número de cursos na modalidade a distância. No Nordeste, ao contrário do que ocorre no Sudeste, existe certa equivalência entre o total de cursos de instituições públicas e privadas de graduação presencial, o que se pode ser explicado pelo fato de que a população não tem condições de arcar com os custos dessa formação por tratar-se de uma região caracterizada, de modo geral, por
(14) Disponível em: http://portal. inep.gov.br/basica-censo-escolarsinopse-sinopse. Acesso em: 17 mar. 2012

(15) Referência ao documento elaborado pelo Conselho Nacional de Educação em 2007. Disponível em: portal.mec.gov.br/cne/arquivos/ pdf/escassez1.pdf. Acesso em: 20 set. 2010 . 
um baixo poder socioeconômico. No entanto, incluindo os dados da EaD, ainda são necessários mais cursos superiores públicos a fim de atender à grande demanda de egressos do ensino médio e assim fomentar o crescimento social, cultural e econômico da região. Aliado a este panorama, outra necessidade surge a partir dos dados relativos aos professores: esta região tem o segundo maior quadro docente de educação básica do país, mas paradoxalmente ocupa o último lugar no que se refere à formação profissional dos mesmos. Isto porque na região Nordeste a maior parte dos professores atuantes na educação básica tem apenas formação em nível médio. Neste contexto, a UAB encontra lugar para alcançar o seu objetivo primeiro, ou seja, oferecer curso de formação inicial e continuada a professores em serviço que não tem formação específica na área em que atuam (BRASIL, 2006), mas, como já foi dito, o oferecimento de cursos nesta região não é representativa de sua demanda.

As regiões Centro-oeste e Sul parecem ser as mais privilegiadas em termos de oferta de cursos superiores de formação de professores. No panorama da profissionalização dos docentes da educação básica, ambas as regiões apresentam mais de 78\% dos seus professores com formação superior. No entanto, relacionando área territorial, número de instituições de educação superior e número de cursos presenciais de graduação, o Centro-oeste requer uma maior demanda de oferta de cursos, visto que sua área é quase o triplo da área da região Sul, a qual desponta no cenário de cursos oferecidos pela UAB.

\section{Acesso $=$ democratização?}

Analisando comparativamente os dados do Quadro 4, os quais foram obtidos a partir dos censos da educação superior de 2006 a 2010, observa-se que os números apresentam uma realidade problemática para a área da Educação a Distância no que se refere ao acesso no ensino superior nesta modalidade. A variação entre o número de vagas ofertadas e a quantidade de alunos ingressantes regista o fato de que mais da metade das vagas não são preenchidas. Em 2008, por exemplo, apenas 27,24\% das vagas nacionais foram ocupadas e é no setor privado que se encontra a maior parte (mais de 80\%) das vagas ociosas. Giolo (2010, p. 1272-1273) declara que "estabelecido o marco regulatório mínimo e preliminar [...], a 
educação superior começou uma vertiginosa corrida expansionista, [onde] a oferta não obedeceu à demanda, sendo sistemática e progressivamente superior a esta".

Tabela 4 - Dados dos cursos de graduação a distância (2006 - 2010)

\begin{tabular}{|c|c|c|c|c|c|c|c|}
\hline \multicolumn{8}{|c|}{ Todas as organizações acadêmicas } \\
\hline & & $\begin{array}{l}\text { Vagas } \\
\text { Oferecidas }\end{array}$ & $\begin{array}{l}\text { Candidatos } \\
\text { Inscritos }\end{array}$ & Ingressos & Matrículas* & Cursos & Concluintes \\
\hline Brasil & 2006 & 813.550 & 430.229 & 212.246 & 207.206 & 349 & 25.804 \\
\hline Brasil & 2007 & 1.541 .070 & 537.959 & 329.271 & 369.766 & 408 & 29.812 \\
\hline Brasil & 2008 & 1.699 .489 & 708.784 & 463.093 & 727.961 & 647 & 70.068 \\
\hline Público & & 254.477 & 313.880 & 183.238 & 278.988 & & 8.175 \\
\hline Privado & & 1.445 .012 & 394.904 & 247.021 & 448.973 & & 61.893 \\
\hline Brasil & 2009 & 1.561 .715 & 665.839 & 332.469 & 838.125 & 844 & 132.269 \\
\hline Público & & & & 43.186 & 172.696 & 400 & 19.073 \\
\hline Privado & & & & 289.283 & 665.429 & 444 & 113.196 \\
\hline Brasil & 2010 & 1.634 .118 & 690.921 & 380.328 & 930.179 & 930 & 144.553 \\
\hline Público & & & & 40.174 & 181.602 & 424 & 12.190 \\
\hline Privado & & & & 340.154 & 748.577 & 506 & 132.363 \\
\hline
\end{tabular}

Uma possível justificativa para esta situação é o próprio sistema de organização da UAB, o qual deposita nos polos de apoio presencial grande parte das responsabilidades pedagógicas e administrativas. Com isso, os municípios passam a ter uma sobrecarga nas suas funções, uma vez que no âmbito nacional a educação organiza-se da seguinte forma: compete à União o ensino superior; os Estados ocupam-se prioritariamente do ensino médio; e é da alçada dos Municípios a educação infantil e o ensino fundamental, especialmente até o nono ano. ${ }^{14}$ Com relação aos municípios, a LDB (MEC, 1996, grifo nosso) sanciona que estes se incumbirão de "oferecer a educação infantil em creches e pré-escolas, e, com prioridade, o ensino fundamental, permitida a atuação em outros niveis de ensino somente quando estiverem atendidas plenamente as necessidades de sua área de competência". No entanto, é de conhecimento geral os problemas educacionais do país, onde muitas das
(14) A organização da Educação nacional está formalmente descrita na no Título IV da Lei de Diretrizes e Bases da Educação Nacional (LDBN 9394/96). Disponível em: http://www.planalto.gov.br/ccivil_03/ leis/L9394.htm. Acesso em: 20 mar. 2012. 
(15) Para informações sobre o IDEB, acessar http://portalideb. inep.gov.br/. escolas não conseguem atingir as metas do Índice de Desenvolvimento da Educação Básica (IDEB) ${ }_{1}^{15}$ por exemplo.

Neste contexto, os Municípios assumem, além daquilo que thes compete, o ensino superior por meio dos polos da EaD/UAB e, conforme Cerny (2009), dadas as diferenças socioeconômicas de cada região do país, muitos municípios não dispõem de condições físicas, financeiras e de pessoal para a manutenção dos polos, o que prejudica o sucesso da modalidade a distância como um todo. Deste modo, acredita-se inclusive que esta responsabilização pode contribuir para o aumento das desigualdades entre os municípios, dadas que suas condições diferem completamente uns dos outros, o que, consequentemente, contribui também para que a democratização não se efetive na prática.

Figura 1- Mapa dos polos UAB em Santa Catarina (abril/2012).

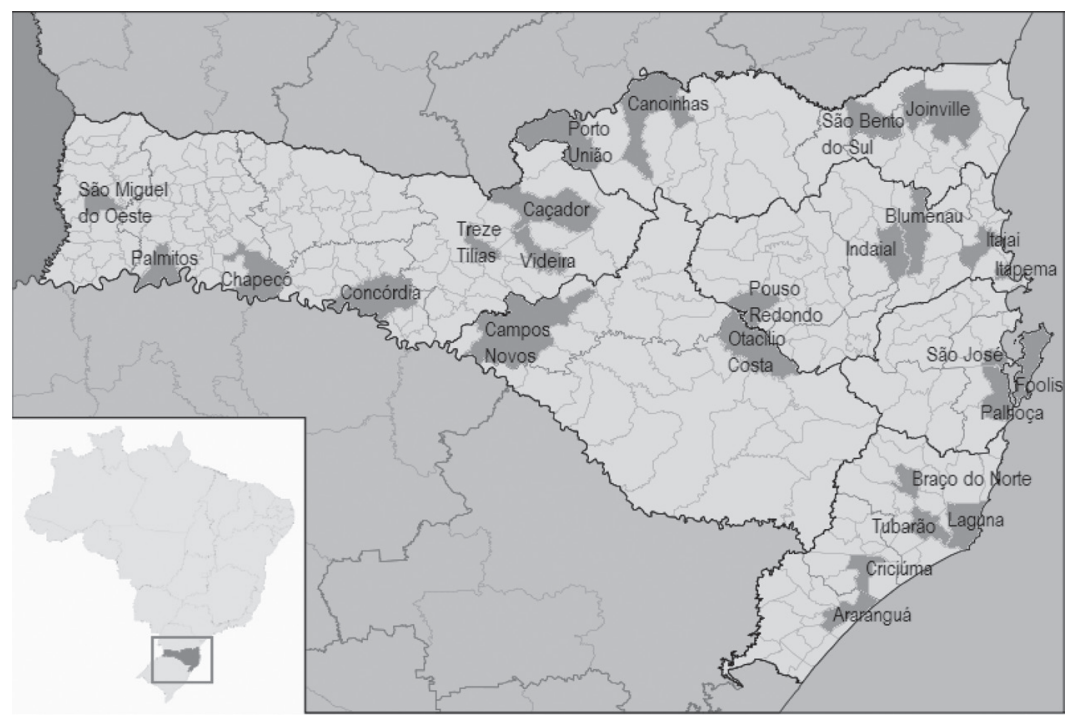

Outro ponto importante, ainda com relação aos municípios, é a questão da interiorização da oferta de cursos e programas de educação superior no país - uma das finalidades da UAB. (BRASIL, 2006) Tomando como exemplo o mapa dos polos da EaD/UAB em Santa Catarina (Figura 1), é possível observar que, no caso catarinense, a pretendida interiorização se dá de modo concentrado, isto é, cursos superiores são ofertados em municípios geograficamente muito próximos de modo que habitantes de outras cidades não têm o real acesso aos cursos, ainda que resida na região geográfica do polo. De acordo com o mapa, a região da grande Florianópolis, por exem- 
plo, -privilegiada por conter a capital do Estado e as sedes de duas universidades públicas (uma estadual e uma federal) - conta com três cidades com polos UAB as quais se concentram no contorno da capital. Deste modo, os habitantes de outras cidades da região terão que se deslocar ao eixo Palhoça/São José/Florianópolis para poder realizar um curso superior. Essa lógica de "vizinhança geográfica" de polos acontece também com Blumenau e Indaial, Araranguá e Criciúma, Laguna e Tubarão, Videira e Caçador, entre outras.

Este mapa evidencia também a problemática de distribuição equilibrada de polos por região. O Planalto Serrano, por exemplo, visivelmente a segunda maior extensão territorial do Estado, tem apenas dois polos ao passo que a região sul possui um território menor e um número maior de polos (cinco). Dos dois polos localizados na serra catarinense, um deles segue a lógica da "vizinhança geográfica" mencionada acima, visto que o município de Otacílio Costa faz fronteira com Pouso Redondo, cidade da região do Vale do Itajaí. Tem-se consciência que um dos requisitos para o credenciamento de polos é o interesse (e a contrapartida) das prefeituras, mas acredita-se ser importante a (re)avaliação desta dinâmica de distribuição de polos.

Somada às questões relativas aos municípios, Cerny (2009) aponta também a necessidade de voltar o olhar para o contexto das instituições, uma vez que as universidades precisam dar conta da nova demanda - a EaD - com os mesmos recursos humanos, ou seja, os mesmos professores e demais profissionais que atuam no ensino presencial. A autora destaca que

[...] caso não sejam dadas as condições adequadas para as universidades e municípios manterem os cursos em andamento, poderemos estar repetindo os mesmos erros do passado, ou seja, grandes programas governamentais com pouco alcance e sucesso. Teríamos, ainda, a inversão da propalada democratização do ensino superior, visto que somente os municípios com maior poder aquisitivo teriam condições de assumir e manter os programas de ensino superior regularmente. Do lado das universidades, a situação não é diferente, pois as condições atuais impedem que estas iniciativas se tornem permanentes. (CERNY, 2009, p. 52-53)

Neste sentido, Pretto e Picanço (2005, p. 46), assinalam uma situação preocupante, pois 
a EaD no ensino superior está vinculada a uma forma de enfrentamento da própria crise da universidade. Existem perspectivas que ocultam esta crise, considerando a EaD como a solução para o ensino superior e, neste caso, ela vem sendo usada para aumentar a capacidade de atendimento das universidades sem que sejam alteradas as péssimas condições de financiamento das mesmas, sem que seja criada uma política justa para o corpo de professores, sem que sejam resolvidas as disparidades de condições do ensino superior entre as regiões do país, entre outras. Tal "solução inovadora" apenas amplia a capacidade de atendimento à grande maioria dos alunos adultos e trabalhadores, mas está descomprometida da oferta de um ensino de qualidade quando não altera as precárias condições que atingem o ensino superior.

Neste contexto, observa-se a urgência da adoção de uma perspectiva mais crítica sobre as políticas educacionais vigentes e em relação à democratização da Educação, uma vez que esta parece não se efetivar na prática por diversos motivos, alguns deles citados acima. O panorama aqui descrito indica que as ações governamentais que se referem à ampliação do acesso à educação superior pública - quarto objetivo da UAB (Decreto n 5.800/06), não oferecem condições substanciais para um melhor aproveitamento das vagas oferecidas. Em outras palavras, simplesmente visar a ampliação não garante o êxito da política: se fazem necessárias outras políticas ou uma ação mais contundente que abarque também o incentivo à inserção e permanência nessas vagas.

Outro fator importante é que ainda hoje persiste uma "lógica de expansão predominantemente privada", tal como detectou Dourado (2008) em análise realizada com base em dados do Censo da Educação Superior de 2006. Naquela ocasião, o autor relatou que $96,12 \%$ das vagas oferecidas em cursos a distância estavam vinculadas ao ensino superior privado. Analisando os dados do mesmo indicador em 2008, comprova-se que a lógica privatista continua consolidando-se como tendência: uma simples observação aos números do Quadro 4 pode evidenciar isto, ou seja, das vagas oferecidas para o ensino superior a distância em 2008, 85,02\% relacionam-se ao setor privado enquanto o ensino público responsabiliza-se por uma pequena fatia (menos de 15\%), apesar da política de expansão via UAB. Os dados de ingresso e matrícula dos Censos de 2009 e 2010, por sua vez, mostram que o setor privado tem se configurado como a principal categoria administrativa 
na expansão do ensino superior via modalidade a distância: em 2009, o setor público representou apenas 12,98\% dos ingressos e 20,26\% das matrículas, ao passo que em 2010 esses percentuais são de 10,56\% e 19,52\%, respectivamente.

Com relação à oferta de cursos, a área da educação deixou de ser prioridade. Segundo Dourado (2008, p. 901), "a área de educação respondia, em 2006, por 64,02\%" das vagas oferecidas, mas os dados revelam que nos últimos dois anos (Quadro 5) ela perdeu espaço para a área de Ciências Sociais, Negócios e Direito, a qual aparecia na segunda colocação em 2006. Ou seja, inverteu-se a sequência da oferta de vagas por área do conhecimento: em 2009 a Educação é responsável por 28,07\% e as Ciências Sociais, Negócios e Direito contam com 50,41\%; em 2010, ainda que a diferença diminua entre as duas áreas, os índices ainda indicam que a prioridade deixa de ser cursos na área educacional.

Quadro 5 - Áreas do conhecimento com maior destaque no cenário de oferta de cursos superiores a distância

\begin{tabular}{|l|l|l|l|l|l|l|}
\hline \multicolumn{2}{|l|}{ Total (todas as organizações acadêmicas) } \\
\hline & \multicolumn{2}{|l|}{ Vagas Oferecidas } & \multicolumn{2}{l|}{$\begin{array}{l}\text { Candidatos } \\
\text { Inscritos }\end{array}$} & \multicolumn{2}{l|}{ Ingressos } \\
\cline { 2 - 8 } & 2009 & 2010 & 2009 & 2010 & 2009 & 2010 \\
\hline Total & 1.561 .715 & 1.634 .118 & 665.839 & 690.921 & 308.340 & 332.028 \\
\hline Áreas com maior destaque & & & & & \\
\hline $\begin{array}{l}\text { Ciências Sociais, } \\
\text { Negócios e Direito }\end{array}$ & 787.307 & 737.265 & 285.216 & 300.473 & 124.647 & 145.715 \\
\hline $\begin{array}{l}\text { Educação } \\
\text { Saúde e }\end{array}$ & 438.429 & 591.008 & 264.345 & 261.106 & 130.702 & 128.235 \\
\hline $\begin{array}{l}\text { Bem-Estar Social } \\
\text { Ciências, } \\
\text { Matemática e } \\
\text { Computação }\end{array}$ & 109.580 & 119.030 & 43.160 & 50.123 & 23.676 & 21.614 \\
\hline
\end{tabular}

Essa inversão vai de encontro ao primeiro objetivo da UAB: "oferecer, prioritariamente, cursos de licenciatura e de formação inicial e continuada de professores da educação básica" (BRASIL, 1996, grifo nosso). Aliás, esse objetivo é duplamente contrariado pelos dados oficiais dos últimos dois anos. Primeiro, como mencionado, cursos de educação deixaram de ser prioridade. Segundo, destaca-se a presença de cursos de características técnicas combinados a cursos de formação de professores para a educação 
básica, nos índices relativos à educação. Ou seja, retirando desses índices os números relativos aos cursos de formação de professor de computação (informática), de disciplinas do setor primário (agricultura, pecuária, etc.), de enfermagem e licenciatura para a educação profissional e tecnológica, a área de educação terá percentuais ainda menores.

\section{Considerações finais}

Ao analisar o contexto da educação a distância, verifica-se que no período entre 1990 e início dos anos 2000 uma gama de ordenamentos legais são publicados visando dar sustentação à política de expansão do ensino superior por meio desta modalidade. Especificamente no âmbito da formação de professores realizada por meio do sistema Universidade Aberta do Brasil, verifica-se que a política em curso apresenta uma série de entraves para que se efetive enquanto possibilidade de democratização do ensino superior público.

O confronto entre dados quantitativos de uma série de fontes possibilitou a realização de uma análise qualitativa do cenário da formação de professores no Brasil. Uma das constatações desta análise evidencia que os dados sobre a oferta de cursos realizados por meio da UAB apresentam incoerências na divulgação realizada pela instituição responsável por este sistema, a CAPES. Por outro lado não há garantia que os dados publicados pelas IPES sejam atualizados e precisos. Constata-se também a existência de uma enorme discrepância entre os dados disponibilizados pelas IPES e os publicados pela UAB. Este panorama de imprecisões conduz a uma primeira conclusão que se apresenta como questionamento: como o governo brasileiro pode oferecer uma equidade de oferta de cursos se desconhece os números reais de suas políticas educacionais?

Ao analisar o alcance da UAB e a consequente expansão da educação a distância no país - observando a oferta de cursos entre as regiões geográficas e considerando o levantamento realizado a partir das IPES/EaD -, os dados indicam o Sul como a região mais representativa em relação ao número de cursos ofertados, seguida pelo Nordeste e Sudeste. Isto significa que duas das três regiões - Sul, Sudeste e Centro-oeste - mais desenvolvidas do Brasil concentram a maior parte dos cursos de formação de professores. 
Adicionado a esses números, o quantitativo da população apta ao ingresso no ensino superior a região Sudeste apresenta o maior contingente, seguida da região Nordeste. A região Norte, por sua vez, apresenta, contraditoriamente, o maior número de professores sem graduação (ao focar a formação em licenciatura, esses números são ainda mais críticos) e a penúltima colocação em termos de oferta de cursos de formação de professores por meio da EaD. De modo similar, a região Nordeste tem o segundo maior quadro docente de educação básica do país, mas paradoxalmente ocupa o último lugar no que se refere à formação profissional dos docentes: a maior parte destes tem apenas formação em nível médio. Isso indica que essa região demanda maior atenção das políticas públicas com relação à oferta de cursos superiores. Na contramão da realidade do Norte e Nordeste, as regiões Centro-oeste e Sul parecem ser as mais privilegiadas tanto em termos de oferta de cursos superiores de formação de professores, quanto no panorama de profissionalização do corpo docente da educação básica, pois ambas as regiões apresentam mais de $78 \%$ dos seus professores com formação superior.

Outro dado preocupante é a variação entre o número de vagas ofertadas e a quantidade de alunos ingressantes onde mais da metade das vagas não são preenchidas. As vagas ociosas encontram-se em maior quantidade nas instituições privadas, sendo estas instituições que tem uma oferta massiva na modalidade a distância. O número de vagas ofertadas na EaD nas instituições públicas é infinitamente menor.

Por fim, a análise evidencia a necessidade de avaliação e revisão constante da atual política implementada por meio do sistema UAB para cursos a distância, no sentido de que as ações empreendidas alcancem de modo mais efetivo os objetivos fixados por esta politica educacional. Não obstante às distorções evidenciadas na política de formação de professores por meio da Universidade Aberta do Brasil, é mister destacar a importância democratizante que esta política representa para o ensino superior público deste país e que outra relevante contribuição é a disseminação da modalidade a distância em universidades tradicionais o que pode representar, num futuro próximo, transformações nos processos de ensino aprendizagem destas instituições. 


\title{
UAB: democratization of public higher education or reproduction of the differences?
}

\begin{abstract}
: this article presents and examines a teaching training panorama sustained by the Distance Education (EaD), linked to the Universidade Aberta do Brasil (UAB) system. The objective was investigate if the current public policies, effected by the UAB system, democratize the public higher education. Thereunto, it has been searched a statistics data series to contextualize the teacher training sustained by the EaD. The public policies have been prioritized the distance mode to ease the teacher training historical necessity in Brazil and therefore public universities are summoned for, a short period of time, to educate a huge numbers of teachers. It is an exploratory research, descriptive and there is an qualitative and quantitative approach. For the collecting and analyzing data it has been done a mapping on teacher training sustained in the distance mode, through the Universidade Aberta do Brasil (UAB), in which was effected in a nationwide and using as database the portals: UAB, Coordenação de Aperfeiçoamento de Pessoal de Nível Superior (CAPES), Instituições Públicas de Ensino Superior (IPES). It has been used, as well, the data of the Censo da Educação Superior and then Instituto Brasileiro de Geografia e Estatística (IBGE). Based on this scenario, the article was developed from two main points: expansion and internalization of public higher education and the teaching training policy in the distance mode.
\end{abstract}

Keywords: Distance Education. Teacher Training. Higher Education. Open University of Brazil.

\section{Referências}

ALONSO, K. M. A expansão do ensino superior no Brasil e a EaD: dinâmicas e lugares. Educ. Soc. v. 31, n. 113, p. 1319-1335, 2010. Disponível em: http://www.scielo.br/pdf/es/v31n113/14.pdf . Acesso em: 15 fev.2011.

BARRETO, R. G. As tecnologias na política nacional de formação de professores a distância: entre a expansão e a redução. Educ. Soc., Campinas, v. 29, n. 104, out. 2008. Disponível em: < http://www. scielo.br/scielo.php?script $=$ sci_arttext

$\mathcal{E} \mathrm{pid}=\mathrm{S} 0101-73302008000300013 \mathcal{E} 1 \mathrm{ng}=\mathrm{enE} \mathrm{nrm}=$ iso $>$. Acesso em: 15 fev.2011.

BRASIL. Lei $n^{\circ}$ 9.394, de 20 de dezembro de 1996. Estabelece as diretrizes e bases da educação nacional. Leis ordinárias. Brasília: Casa Civil da Presidência da República Federativa do Brasil/Subsecretaria para Assuntos Jurídicos, 1996. Disponível em: < http://www.planalto. gov.br/ccivil_03/Leis/L9394.htm >.

- Decreto $n^{\circ}$ 5.800, de 8 de junho de 2006. Dispõe sobre o Sistema Universidade Aberta do Brasil - UAB. Brasília: Casa Civil da Presidência da República Federativa do Brasil/Subchefia para Assuntos Jurídicos, 1996. Disponível em: < http://www.uab.capes.gov.br/images/stories/ downloads/legislacao/decreto5800.pdf > . 
Portal do Instituto Brasileiro de Geografia e Estatística.

Disponível em: < http://www.ibge.gov.br/home/ > . Acesso em: 12 abr. 2012.

CAVALCANTI. C.C; STROZZI.G. Democratização do ensino no Brasil: reflexões sobre Inclusão Digital e Direitos Humanos. São Paulo. 2008. Disponível em: http://Www.distanceandaccesstoeducation.org/ contents/OP-Cavalcanti-Strozzi.pdf.

Acesso em: 13 ago. 2011.

CERNY, R. Z. Gestão pedagógica na educação a distância: análise de uma experiência na perspectiva da gestora. 2009. $257 \mathrm{f}$. Tese (Doutorado em Educação) - Faculdade de Educação, Pontifícia Universidade Católica de São Paulo, São Paulo, 2009.

DOURADO, L. F. Políticas e gestão da educação superior a distância: novos marcos regulatórios?. Educ. Soc., v. 29, n. 104, p. 891-917, out. 2008. Disponível em http://www.scielo.br/pdf/es/v29n104/a1229104. pdf. Acesso em: 21 fev. 2011.

FRAGALE FILHO, R.; ROVER, A. J.; BACHA FILHO, T. Educação a distância: análise dos parâmetros legais e normativos. Rio de Janeiro: DPEA, 2003. 179p. (Educação a distância)

GATTI, B. A.; BARRETO, E. S. de S. (Coord). Professores do Brasil: impasses e desafios. Brasilia: Unesco, 2009.

HOUAISS, A.; VILLAR, M. de S. Dicionário Houaiss da língua Portuguesa. Rio de Janeiro: Objetiva, 2009.

LITWIN, E. (Org.). Educação a distância: temas para o debate de uma nova agenda educativa. Tradução Fátima Murad. Porto Alegre: Artmed, 2001.

MARTINS, O. B. Os caminhos da EaD no Brasil. Revista Diálogo Educativo, Curitiba, v. 8, n. 24, 2008. Disponível em: < http://www2. pucpr.br/reol/index.php/DIALOGO?dd $1=2012 \& d d 99=$ view $>$. Acesso em: 14 fev. 2011.

PORTAL UAB. Disponível em: < http://uab.capes.gov.br/index. php?option $=$ com_contentEview $=$ articleE $\mathrm{id}=9 \mathcal{E}$ Itemid $=21$ > Acesso em: 10 out.2011.

PRETI, O. (Org.). Educação a distância: sobre discursos e práticas. Brasília, DF: Liber Livro, 2005.

PRETTO, N. de L; PICANCO, A. de A. Reflexões sobre EaD: concepções de educação. In: ARAÚJO, B; FREITAS, K. S. Educação a distância no contexto brasileiro: algumas experiências da UFBA. Salvador: ISP/UFBA, 2005. p. 31-56.

SANTOS, F. C. UAB como política pública de democratização do ensino superior via EaD. 2011. Disponível em: < http://www.anpae.org.br/ simposio2011/cdrom2011/trabalhosCompletos01.htm > . Acesso em: 10 out. 2011. 
VARGAS, H. M. Democratização no ensino superior brasileiro: entre a intenção e as possibilidades. 2007. Disponível em: < http://WWW. anped11.uerj.br/30/ > . Acesso em: 10 out 2011.

Recebido: 10/08/2012 | Aprovado: 15/01/2013 